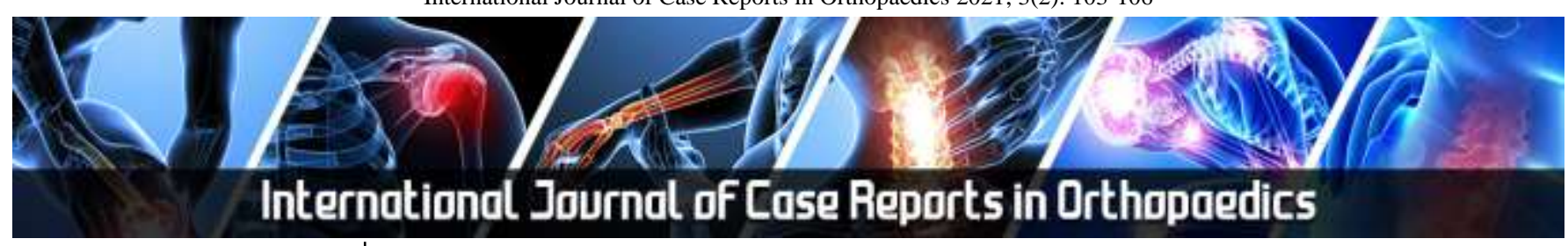

E-ISSN: 2707-8353 P-ISSN: 2707-8345 IJCRO 2021; 3(2): 103-106 Received: 22-06-2021 Accepted: 25-07-2021

\section{Bailey MacInnis}

Carle Illinois College of Medicine, $807 \mathrm{~S}$ Wright St, Champaign, IL 61820, United States

Robert Bane MD

Carle Foundation Hospital, 611 W Park St, Urbana, IL 61801, United States
Corresponding Author: Bailey MacInnis Carle Illinois College of Medicine, $807 \mathrm{~S}$ Wright St, Champaign, IL 61820, United States

\section{Rare and often underestimated: A literature review and case report of isolated, proximal semimembranosus injury}

\author{
Bailey MacInnis and Robert Bane MD
}

DOI: https://doi.org/10.22271/27078345.2021.v3.i2b.76

\begin{abstract}
Isolated and Retracted avulsion of the proximal semimembranosus tendon is exceedingly rare. Current literature suggests that most hamstring tears involving only one of the three muscles can be managed with conservative treatment. However, the semimembranosus contributes significantly to the strength and flexibility of the hamstring and even isolated tears may lead to long term consequences. We present a literature review and case report of isolated, proximal semimembranosus tears. Especially in the case of an elite athlete, such as an NCAA American football player presented here, a retracted, proximal semimembranosus avulsion may require surgical management to ensure return of strength, speed, and flexibility that will allow this athlete to continue to compete.
\end{abstract}

Keywords: Semimembranosus avulsion hamstring avulsion proximal semimembranosus football case report

\section{Introduction}

Acute hamstring injuries are common among athletes of all levels however, hamstring avulsions account for only $3-11 \%$ of hamstring injuries ${ }^{[1]}$. In fact, there have been only a few documented cases of isolated and retracted ruptures of the proximal semimembranosus muscles.

Clinical decision making in hamstring injuries is varied and depends on the extent of the injury. The literature suggests that tears that include more than 2 of the 3 hamstring muscles with significant displacement $(>2 \mathrm{~cm})$ should be repaired surgically while hamstring tears including only 1 muscle can be managed with conservative treatment ${ }^{[2,3]}$. While this seems to hold true for most hamstring injuries, proximal, isolated semimembranosus avulsions with significant retraction may present a different story.

The authors of this work present a case of an American football player and a systematic review of case reports on isolated proximal semimembranosus avulsions. We aim to explore the necessity of surgical management and evaluate return to play outcomes.

\section{Methods}

A search was conducted in PubMed and Scopus for full text case reports using the search words, proximal, semimembranosus, tear, avulsion, and rupture with appropriate Boolean modifiers. The available case reports were then evaluated for relevance to isolated, proximal semimembranosus avulsions. In total, 2 case reports on 2 patients met the necessary criteria.

\section{Results and Discussions}

\subsection{Case Report}

\subsubsection{Presentation}

A 22-year-old male, American football player who presents with an acute hamstring injury during a game. The patient was catching a pass when he was tackled into a position that forced hyperflexion of the hip with extension of the ipsilateral knee. Upon injury, the patient was unable to walk without assistance. He reported generalized pain in the posterior thigh that localized to the proximal and posterior medial thigh in the days following the injury.

MRI imaging of the right thigh (Figure 1) revealed proximal avulsion of the semimembranosus tendon with a $7 \mathrm{~cm}$ retraction. 


\subsubsection{Surgical Repair}

The patient underwent surgical repair (Figure 2) 10 days after the injury. With the patient in a prone position and a longitudinal incision was made starting at the gluteal crease to provide access to the distally retracted tendon. The posterior femoral cutaneous nerve was identified and protected and the fascia of the gluteus maximus was divided to expose the ischial tuberosity. The avulsed semimembranosus was located by dissecting medially along the semitendinosus and then retracting posteriorly and medially. 2.2 Fiberwire in a Krakow fashion was used to attach to the semimembranosus tendon. The sciatic nerve, posterior femoral cutaneous nerve, and its pudendal branches were identified and protected. Blunt dissection was used at the proximal and lateral borders of the biceps femoris up to the ischial tuberosity. The ischial tuberosity was then prepared using a sharp elevator. A long hemostat was used to pass the Fiberwire sutures along the semimembranosus deep to the semitendinosus and the biceps femoris to the lateral side of the ischial tuberosity. The Fiberwire sutures were passed through the eyelet of a super MiTek anchor (4 pronged) and the anchor was deployed into the ischial tuberosity. The knee was flexed to allow the tendon to fall into its anatomic place and the sutures were tied and cut.

Following the reconstruction, the knee was able to fully extend without excessive tension. The wound was thoroughly irrigated. After ensuring good hemostasis, the wound was closed with care to avoid encasement of the posterior cutaneous femoral nerve. An occlusive dressing was placed followed by an ACE bandage wrapping from the groin to the foot.

\subsubsection{Post-Operative Course}

To ensure proper recovery of the semimembranosus tendon, the hamstring remained relatively immobile for the first 4 weeks post op. From there, a gradual progression was used to regain strength and flexibility.

At 4 weeks, light rehabilitation began and by 6 weeks light stretching was added to the rehabilitation regimen to begin to improve flexibility of the muscle.

During weeks 6-12, the patient was weaned off the crutches and progressed to exercise with elliptical machine and recumbent bike. At this point, we avoided using a traditional bike to avoid direct pressure on the ischial tuberosity from sitting.

At 16 weeks, low impact underwater running was started. From 18-22 weeks, a land run progression was started. The progression concluded with full speed linear running. At this point, the patient's flexibility was close to his pre-injury benchmarks, but hamstring strength and explosiveness was still diminished. During week 24, the patient resumed plyometric training and sport specific training.

By 1 year he was cleared functionally cleared for full participation. Note that this clearance was slightly delayed by the onset of the COVID-19 pandemic which delayed the American football NCAA spring season.

\subsection{Literature Review}

Given the paucity of available cases reported in the literature isolated, proximal semimembranosus injuries appear to be exceedingly rare (Table 1$)^{[4,5]}$. Interestingly, the semimembranosus is the deepest of the three hamstring muscles which may make accurate diagnosis without MRI difficult. This highlights the need for a heightened sense of suspicion if the patient's clinical presentation seems worse than what would be anticipated based on physical findings. Moreover, the semimembranosus contributes significantly to the strength of the hamstring muscles. Difficulty in diagnosis and loss of strength, caused by injury, in combination with the proximity to the sciatic nerve, could lead to long term impairment without proper management. Unfortunately, neither of the cases presented in the literature search feature an elite athlete such as the 22 yo American football player featured in our case. In the case of an elite athlete, good outcomes are dependent on return to play with sufficient strength, speed, and flexibility which in the setting of a significantly retracted, isolated, proximal semimembranosus tear may be difficult to obtain without surgical management.

\section{Conclusion}

The hamstring consists of 3 muscles: the biceps femoris, semimembranosus, and semitendinosus. Except for the short head of the biceps femoris, the hamstring muscles originate at the ischial tuberosity. Distally, the hamstring muscles combine to form the superolateral (biceps femoris) and superomedial (semimembranosus and semitendinosus) borders of the popliteal fossa. The semimembranosus which runs the deepest of all the hamstring muscles, contributes significant strength to the hamstring muscle group.

The most common mechanisms of proximal hamstring avulsions are slip and fall accidents or hip hyperflexion with knee extension ${ }^{[1]}$. Common clinical signs of acute hamstring injuries include pain in the buttock, weakness of knee flexion, tenderness distal to the ischial tuberosity, and a palpable defect in the posterior thigh.

In many cases, minor hamstring injuries can be diagnosed and managed clinically without the need for MRI. However, proximal tenderness at the ischial tuberosity, severe clinical symptoms, or bruising may warrant MRI to evaluate for more significant injury.

Complete avulsion of all three tendons or avulsion of 2 tendons displaced greater than $2 \mathrm{~cm}$ are indications for surgical repair. We hypothesize that because of the size and function of the semimembranosus, isolated and significantly retracted tears of this tendon may be another indication for surgical repair. 


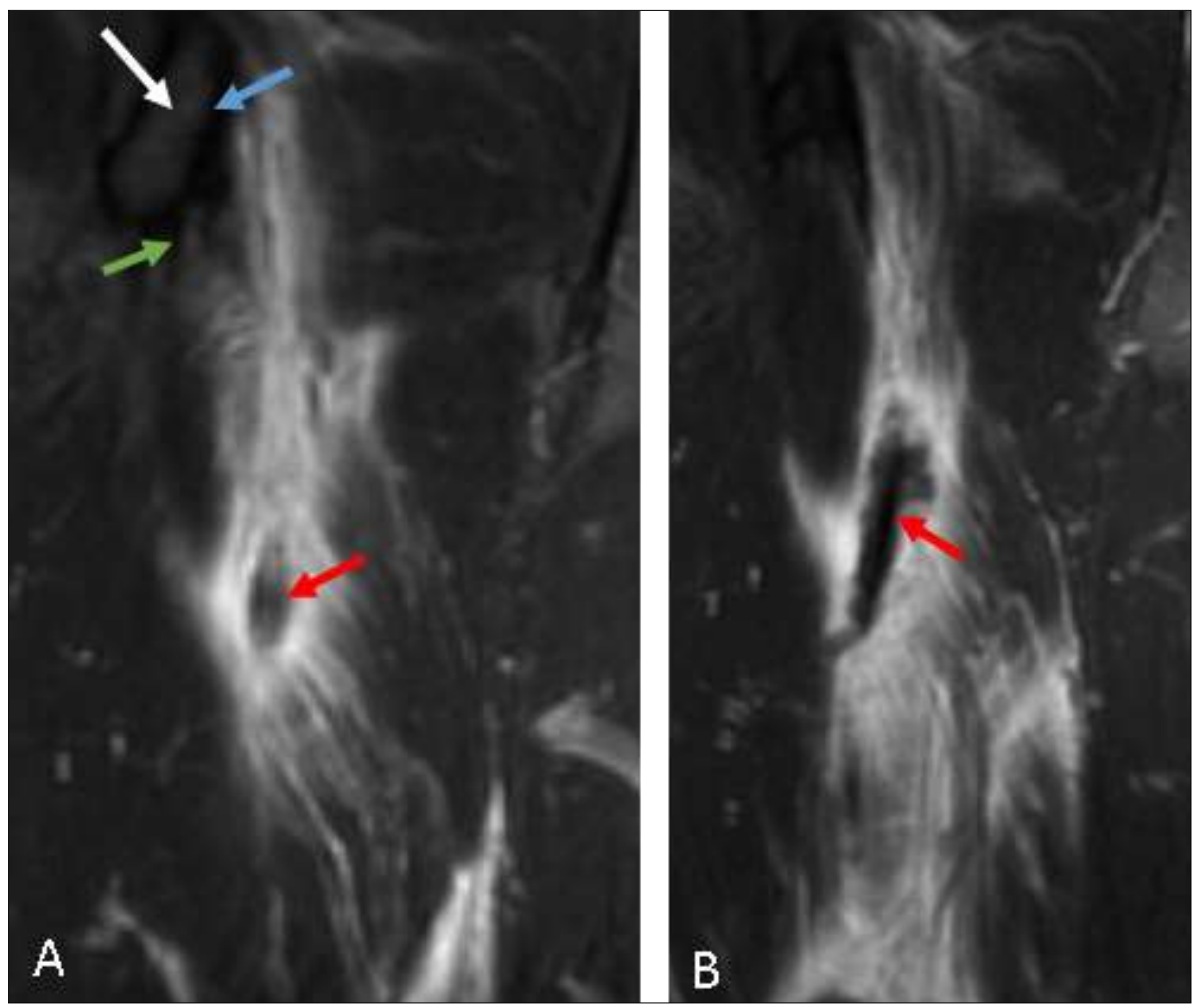

Fig 1: Coronal MRI images of the right thigh for 22-year-old male American football player. The red arrows denote the retracted semimembranosus tendon A) The white arrow denotes the ischial tuberosity. The green arrow denotes the intact conjoint tendon of the biceps femoris and semitendinosus. The blue arrow denotes the origin of the semimembranosus. You can see that there is significant retraction of the semimembranosus from the origin. B) A deeper slice of the MRI image showing a greater portion of the retracted semimembranosus tendon.

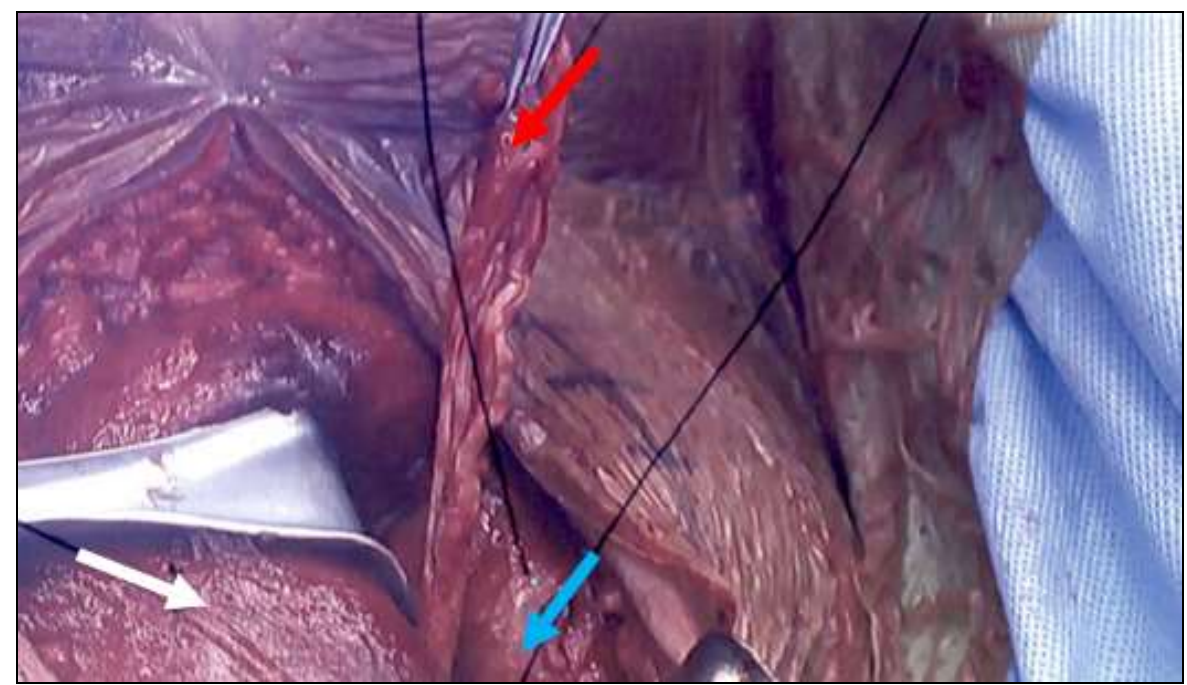

Fig 2: Picture taken during surgical repair of the right semimembranosus $m$. (red arrow). Semitendinosus m. (white arrow) and adductor magnus m. (blue arrow) also shown. The semimembranosus runs deep to the semitendinosus and biceps femoris (not pictured).

Table 1: Systematic review of available case reports on isolated, proximal semitendinosus injuries

\begin{tabular}{|c|c|c|}
\hline Case & Chua et al. (2006) ${ }^{[4]}$ & Regauer et al. (2005) ${ }^{[5]}$ \\
\hline Patient & 30 yo $\mathrm{M}$ & 45 yo \\
\hline Patient Info & $\begin{array}{c}\text { Minimally responsive and tetraplegic } \\
\text { with spasticity following traumatic } \\
\text { brain injury } 5 \text { years prior }\end{array}$ & \\
\hline \begin{tabular}{|c|} 
Activity Leading to \\
Injury
\end{tabular} & Therapeutic stretching & Jogging \\
\hline Clinical Signs & $\begin{array}{c}\text {-Acute thigh swelling with significant } \\
\text { bruising }\end{array}$ & $\begin{array}{l}\text {-"Whip like pain" below the gluteal area, limp with flexion on } \\
\text { ambulation } \\
\text {-Swelling and bruising of posterior thigh, pain on palpation distal } \\
\text { to ischial tuberosity }\end{array}$ \\
\hline
\end{tabular}




\begin{tabular}{|c|c|c|}
\hline & & $\begin{array}{l}\text {-Weakness of knee flexion, } \\
\text {-"Visible defect in continuity" }\end{array}$ \\
\hline $\begin{array}{l}\text { Description of } \\
\text { Injury }\end{array}$ & $\begin{array}{l}\text {-Complete rupture of the right } \\
\text { semimembranosus muscle with } \\
\text { surrounding hematoma }\end{array}$ & $\begin{array}{l}\text {-Complete rupture of the proximal tendon of the semimembranosus } \\
\text { muscle with } 3 \mathrm{~cm} \text { retraction. Passive pain-dependent exercise } \\
\text { while avoiding active knee flexion and hip joint extension as well } \\
\text { as forced hip joint flexion. Splint in } 30^{\circ} \text { knee flexion with } \\
\text { mobilization on forearm crutches up to the } 3 \text { rd postoperative week }\end{array}$ \\
\hline Time to Surgery & 1 day & 18 days \\
\hline Treatment & $\begin{array}{l}\text {-Hematoma evacuated, muscle } \\
\text { debrided, semimembranosus not } \\
\text { sutured. } \\
\text {-ROM exercises }\end{array}$ & $\begin{array}{l}\text {-Surgical reconstruction with Rupturzone self-tapping, titanium } \\
\text { anchor system at the ischial tuberosity }\end{array}$ \\
\hline Outcomes & $\begin{array}{c}\text {-Discharged } 21 \text { days post op. } \\
\text {-By } 1 \text { month post discharge: Modified } \\
\text { ashworth scale } 0 \text { and full passive range } \\
\text { of motion }\end{array}$ & $\begin{array}{c}\text {-Discharged } 3 \text { days post op. } \\
\text {-By } 8 \text { weeks, walking normally without increased hip flexion. } \\
\text {-By } 6 \text { months, symptom free in everyday life- some pain in rear leg } \\
\text { after sitting for a prolonged time }\end{array}$ \\
\hline
\end{tabular}

\section{References}

1. Van der Made AD, Reurink G, Gouttebarge V, Tol JL, Kerkhoffs GM. Outcome after Surgical Repair of Proximal Hamstring Avulsions: A Systematic Review. Am J Sports Med 2015;43(11):2841-2851. doi:10.1177/0363546514555327

2. Cohen S, Bradley J. Acute Proximal Hamstring Rupture: Journal of the American Academy of Orthopaedic Surgeons 2007;15(6):350-355. doi:10.5435/00124635-200706000-00004

3. Moatshe G, Chahla J, Vap AR, et al. Repair of Proximal Hamstring Tears: A Surgical Technique. Arthrosc Tech 2017;6(2):e311-e317. doi:10.1016/j.eats.2016.10.004

4. Chua DSGK, Kong KH. Complete semimembranosus rupture following therapeutic stretching after a traumatic brain injury. Brain Injury 2006;20(6):669672. doi:10.1080/02699050600676842

5. Regauer M, Kettler M, Schieker M, Kanz KG, Mutschler W. Complete rupture of the proximal semimembranosus tendon. doi:10.1007/s00113-0050943-y 